\section{ARCHIVOS}

de historia del movimiento obrero y la izquierda
ISSN 2313-9749

ISSN en línea 2683-9601

Año VIII, $n^{\circ} 16$, pp. 37-69

marzo de 2020-agosto de 2020

\title{
Teoría de la Reproducción Social. Elementos fundamentales para un feminismo marxista
}

\section{Cinzia Arruzza y Tithi Bhattacharya}

\author{
New School of Social Research \\ (Nueva York, Estados Unidos) \\ arruzzac@newschool.edu
}

\author{
Purdue University \\ (Indiana, Estados Unidos) \\ tbhattac@purdue.edu
}

Titulo: Social Reproduction Theory. Foundations of a Marxist Feminism

Resumen: Este texto recorre los elementos fundamentales de la Teoría de la Reproducción Social en tanto apuesta por un feminismo marxista contemporáneo. Comienza por la definición de qué es la reproducción social bajo el capitalismo y se adentra luego en los debates sobre las relaciones entre producción y reproducción, cuál es el rol que juega la familia, cómo pensar la sexualidad y los derechos reproductivos y cómo pueden ser leídos los procesos de desposesión neoliberal en clave de la reproducción social. Estos tópicos están desarrollados en diálogo con otras tradiciones de la teoría feminista como el materialismo francés, la interseccionalidad, la apuesta por "los comunes" y el autonomismo. Palabras clave: feminismo - marxismo - reproducción social - clase obrera

\begin{abstract}
This text covers the fundamental elements of the Theory of Social Reproduction as it bets on a contemporary Marxist feminism. It begins with the definition of what is social reproduction under capitalism, and then goes into the debates about the relations between production and reproduction; what is the role of the family; how sexuality and reproductive rights can be thought from this point of view; and how can neoliberal dispossession processes be read in terms of social reproduction. This topics are developed in dialogue with other traditions of Feminist theory such as French materialism, intersectionality, the commitment to "the commons" and autonomism.
\end{abstract}

Keywords: Feminism - Marxism - social reproduction - working class

Recepción: 15 de noviembre de 2019. Aceptación: 27 de febrero de 2020 


\section{¿Qué es la reproducción social?1}

Cinzia Arruzza. Hay, al menos, tres esferas en las que se lleva a cabo la reproducción social. Por supuesto, la familia sigue siendo la principal, pero hay toda una serie de trabajos reproductivos que han sido socializados, en los hechos, por el Estado y que se llevan a cabo a través de instituciones públicas (escuelas, hospitales, etc.). La neoliberalización de la reproducción social implica recortes en esos servicios públicos y produce un incremento de la carga de reproducción social en las familias. Eso es lo novedoso: en el neoliberalismo aparece la idea de la reproducción social como un campo que puede ser también fuente de ganancias. Por supuesto que esto es particularmente cierto en países desarrollados y en las zonas urbanas donde buena parte del trabajo de reproducción social puede transformarse, de hecho, en productor de ganancia.

Pero... ¿qué significa reproducir la fuerza de trabajo? En primer lugar, significa regenerar al trabajador o la trabajadora; segundo, significa mantener y regenerar a la familia de la trabajadora (o a las trabajadoras en un sentido ampliado). ${ }^{2}$ Este es un punto central que señala Lise Vogel en su libro: ${ }^{3}$ cuando hablamos de reproducción social tenemos que tener en cuenta que no estamos hablando sólo del trabajador o la trabajadora que intenta vender su fuerza de trabajo en forma directa en el mercado, sino de la clase obrera en su conjunto, incluyendo a los que no trabajan, los niños, los adultos mayores y los enfermos, o sea, todos aquellos que no pueden trabajar. En tercer lugar, significa producir a las nuevas trabajadoras, o sea, la reproducción biológica. También en este punto Vogel realiza una distinción muy importante en su libro. Cuando habla de reproducción generacional de la fuerza de trabajo, ella distingue la reproducción biológica en tanto producción de nuevas trabajadoras, de la reproducción cotidiana de la fuerza de trabajo, en tanto mantenimiento de la fuerza de trabajo. Es decir que la reproducción generacional de la fuerza de trabajo implica, en pri-

1. El texto surge de la transcripción realizada por Paula Varela y Lucas Poy, a partir del audio grabado por Antonio Oliva, que asistió al Niep-Marx 2019. La traducción y edición estuvo a cargo de Paula Varela. Agradecemos a las autoras la autorización para su publicación. Todas las notas al pie son de nuestra edición.

2. Debido a que, en el idioma inglés, los sustantivos (como trabajador/a o trabajadores/as) no tienen género (worker o workers), hemos decidido adoptar el femenino como regla general. De modo que donde dice "trabajadora" o "trabajadoras" no significa que las autoras hayan referido particularmente a trabajadoras mujeres, sino que han referido a trabajadoras mujeres, varones o de cualquier género indistintamente.

3. Marxism and the Oppression of Women (Vogel, 2013), publicado originalmente en 1983 y reeditado con prólogo de Susan Ferguson y David McNally. 
mer lugar, que las trabajadoras tienen que existir, es decir, que tienen que ser producidas biológicamente; pero en segundo lugar, que tienen que reproducirse cotidianamente: necesitan reponer fuerzas no sólo físicamente sino también mental y psicológicamente. Y esto implica la socialización de las futuras trabajadoras, más allá de si tienen chances de ingresar al mercado de trabajo y encontrar un empleo. En este punto de la reproducción generacional de la fuerza de trabajo quisiera subrayar tres elementos. En primer lugar, que hablar de reproducción social implica hablar de una reproducción material, física, de la fuerza de trabajo porque, como es evidente, si nuestros cuerpos no están vivos y no están saludables, no hay reproducción social. Pero la reproducción social también incluye otras actividades destinadas a dar forma, a moldear a las personas. Para ponerlo en palabras simples: no nacemos con una propensión natural a trabajar 8 o 9 horas diarias o a prestar atención en una clase durante 3 horas en un aula (como ustedes están haciendo hoy aquí). Esto no nos surge naturalmente. Debemos ser disciplinadas, debemos ser formateadas para aguantar estar sentadas tres horas en una clase... ¡ incluso disfrutarlo! O estar sentadas durante horas en una computadora o en un puesto de trabajo en una fábrica y, aunque no lo disfrutemos, ser capaces de hacerlo. Entonces, la reproducción social también tiene que ver con la socialización. En otras palabras, la reproducción de actitudes, predisposiciones, habilidades, calificaciones; en cierto sentido es la reproducción de la subjetividad e incluso la internalización de las formas de la disciplina.

Dicho esto, quisiera referirme a dos cuestiones. La primera está relacionada con la pregunta acerca de si hay un reduccionismo biológico ${ }^{4}$ al pensar la reproducción social desde el punto de vista de la reproducción de la fuerza de trabajo. La reproducción biológica es un hecho para la vida. La gente se reproduce biológicamente para vivir. Quizás en un futuro distante nos reproduzcamos en otras formas, pero por ahora, necesitamos tener bebés para reproducirnos, y el feminismo tiene que poder lidiar con esto. Primero porque, aunque no solo las mujeres tienen bebés, en su gran mayoria somos mujeres las que tenemos los bebés. La teoría de la reproducción social no coloca en el hecho de tener bebés, o en la maternidad, la causa de la opresión de las mujeres. Eso sí sería un reduccionismo biológico. Pero eso no es lo que nosotras decimos. El punto está en las relaciones sociales que organizan la reproducción biológica: cómo este hecho vital se transforma en un hecho social. Es decir, cuáles son las relaciones sociales que organizan el embarazo, el parto, el "tener bebés", pero también cuáles

4. Aquí Arruzza hace referencia a una pregunta del público. Para profundizar en esta discusión, véase Arruzza (2015). 
son las relaciones sociales más generales que tienen impacto en el proceso biológico de tener bebés. Entonces, el problema está en el punto de encuentro entre el "hecho biológico" y el "hecho social". No hay ningún destino en la biología, no hay ninguna predestinación en la biología. En una sociedad que no esté orientada a la producción de ganancia (como el capitalismo), la reproducción biológica, el "tener bebés", no tiene porqué ser una fuente de opresión. Podría organizarse de una manera completamente diferente a como es hoy. Entonces, no creo que la teoría de la reproducción social corra un riesgo de sesgo biologicista sino que creo que tiene que hablar de la reproducción biológica porque es una parte importante de lo que las mujeres y los cuerpos gestantes hacen a la hora de reproducir la fuerza de trabajo. Y tiene que hablar de la forma en que la producción industrial de masas (Tithi va a referirse a eso más tarde) sujeta, moldea, incluso esa reproducción biológica. La producción industrial de masas juega claramente un papel fundamental en darle forma a los roles de género en un modo determinado y, de este modo, en generar la opresión de género.

La segunda cuestión debería haberla aclarado al inicio. En la tradición marxista, el término "reproducción social" ha sido usado de diferentes maneras. En la tradición althusseriana, la reproducción social refiere no sólo a la reproducción de la fuerza de trabajo sino a la reproducción de la sociedad capitalista como un todo. Esto incluye, por supuesto, los distintos circuitos del capital, pero también incluye lo que Althusser llama las "condiciones de la producción", la producción de condiciones para la producción, por ejemplo, el Estado, la policía, las fuerzas armadas, los aparatos ideológicos del Estado, etc. Esta es una acepción más amplia del término "reproducción social". En la teoría feminista marxista, la reproducción social refiere a algo más puntual, más estrecho: a la reproducción de la fuerza de trabajo. Esto no es incompatible con la visión althusseriana, el problema es que desafortunadamente se usa el mismo término y eso genera cierta confusión. Johanna Brenner, ${ }^{5}$ por ejemplo, sugiere distinguir entre "reproducción societal" (para referirse a la reproducción del sistema capitalista como un todo) que sería adecuada para la acepción althusseriana, y "reproducción social" para referir a la reproducción de la fuerza de trabajo, que sería la acepción del feminismo marxista. En síntesis, para clarificar, cuando hablamos de "reproducción social" estamos usando la categoría en sentido estrecho, como la usa el feminismo marxista, y eso nos permite hacer foco en el rol del género y de la opresión de género en el capitalismo. Es decir, hacer foco en la pregunta acerca de 
cuáles son las causas de la producción y reproducción de la opresión de género en el capitalismo.

Tithi Bhattacharya. Una de las cosas que la Teoría de la Reproducción Social (TRS) establece claramente es que el trabajo reproductivo todavía es realizado predominantemente por mujeres o cuerpos feminizados. Ese trabajo se supone que es la tarea, el deber e incluso parte del lado amoroso de las mujeres que "naturalmente" lo realizan. ¿Cómo se reproduce socialmente a un niño? Pensemos en las formas por fuera de la familia. Como señaló Cinzia, la TRS nos enseña que la reproducción social no se lleva a cabo solo en la familia sino también en la esfera pública. Pensemos en cierto tipo de servicios públicos: uno es el sistema de salud, otro caso podría ser la escuela, pero incluso la disponibilidad de agua potable o de aire no contaminado. Tomemos esos cuatro elementos básicos que necesitamos para que una niña crezca de un modo saludable. Y miremos Estados Unidos o Inglaterra, o incluso los países escandinavos, y veamos quiénes tienen las peores condiciones de acceso a esos cuatro elementos de la reproducción social. En la ciudad de Chicago, cuando el alcalde demócrata (amigo cercano de Barack Obama) comenzó a cerrar escuelas con el argumento de que era necesario recortar ciertos servicios públicos, lo hizo sólo en el sur de la ciudad, que es donde viven las familias negras y latinas, mientras las escuelas del norte rico de Chicago estaban florecientes. Cuando se cierran las clínicas de Planned Parenthood, que es el principal proveedor de abortos en Estados Unidos y es utilizado sobre todo por mujeres pobres, se está atacando la planificación de la maternidad de las mujeres más pobres. Si se revisan los censos se observa que, en promedio, las familias migrantes viven en espacios un $30 \%$ más pequeños que las familias no migrantes. Y ese porcentaje no surge de la comparación con familias que están por arriba de la línea de pobreza sino entre quienes están debajo de la línea de pobreza. Lo que quiero remarcar es que la reproducción social de las familias de la clase obrera blanca es diferente a aquella de las niñas de las familias de la clase obrera negra. Existe una expansión generalizada de la fuerza de trabajo en el territorio nacional pero hay dos tipos de procesos de reproducción social diferenciados que objetivan dos tipos de trabajadoras distintas al momento en que éstas llegan a las puertas del capital para vender su fuerza de trabajo. Una fuerza de trabajo vale menos y esa trabajadora tiene menos poder que la otra cuya reproducción social ha tenido una historia bien diferente.

Los procesos diferenciados de reproducción de la fuerza de trabajo producen diferentes tipos de sufrimiento y objetivación al momento en que las trabajadoras llegan a la puerta de la fábrica. Comúnmente se 
considera que el racismo opera en la esfera del mercado de trabajo. La interpretación marxista habitual sobre el racismo focaliza el análisis en el mercado de trabajo y explica que el racismo es utilizado y fomentado por el capital para profundizar la competencia entre trabajadoras, dividirlas y gobernar. Pero el mercado de trabajo no es el reino de la producción sino el reino del intercambio. Es decir que las teorias marxistas tradicionales sobre el racismo focalizan la mirada en el terreno del intercambio.

La TRS muestra una imagen mucho más aterradora: que el racismo se despliega en el nivel de la reproducción de la fuerza de trabajo. Las escuelas, los servicios de salud, el agua y el aire envenenados (porque sus casas están construidas cerca de zonas contaminadas por la polución o los desechos industriales): todos esos procesos contribuyen a la construcción de diferentes niveles de fuerza de trabajo y también al mantenimiento de ideas racistas en la sociedad. Lo que proponemos es un análisis del racismo que vaya más allá del nivel del intercambio hacia el dominio de la producción de fuerza de trabajo en sí mismo. En este sentido, es una visión mucho más aterradora del racismo pero también es una idea mucho más sólida del antirracismo, porque analiza al racismo en todos los eslabones de su construcción: en cualquiera de esos eslabones el capital puede ser afectado. Cuando defendemos una escuela pública de los recortes, esa no es solo una lucha en el lugar de trabajo sino que es también una lucha antirracista. Cuando apoyamos al movimiento Black Lives Matter ${ }^{6}$ en el barrio, esa no es solo una lucha antirracista, también ayuda a los derechos laborales porque fortalece a las trabajadoras negras para negociar y conseguir mejores condiciones de trabajo.

\section{La relación entre producción y reproducción}

Cinzia Arruzza. Déjenme comenzar con la cuestión de la relación entre explotación y opresión, y su vínculo con la producción y la reproducción. Uno de los problemas que tenemos en la teoria marxista es que Marx no terminó El capital. Eso produce una tendencia a poner el foco en el volumen 1, que es el único que Marx publicó en vida, como si este volumen fuera la verdad completa de lo que es el capitalismo

6. Black Lives Matter (Las vidas negras importan) es un movimiento social y político surgido en 2013 en Estados Unidos contra la brutalidad policial hacia las personas negras. El hecho que desencadenó el movimiento fue la absolución del policía George Zimmerman luego del asesinato del adolescente afroamericano Trayvon Martin. En 2014, BLM cobró notoriedad a nivel nacional e internacional por sus movilizaciones y protestas luego de los asesinatos de los jóvenes afroamericanos Michael Brown, en Ferguson (estado de Misuri), y Eric Garner, en Staten Island (estado de Nueva York). 
y de cómo funciona. Y lo cierto es que el proyecto era mucho mayor, originariamente estaban planificados seis libros. En la versión editada por Engels tenemos dos volúmenes más, uno sobre la circulación y otro sobre la reproducción del capitalismo como un todo y la acumulación de capital. Desafortunadamente, esos son materiales fragmentarios que fueron editados por Engels. Todo esto genera mucha ambigüedad, mucha confusión y también muchos malentendidos. Digo esto porque una cosa es decir que la extracción de plusvalía sigue siendo el corazón del capitalismo y otra cosa son las consecuencias que pueden sacarse de esto.

Una primera consideración, y uno de los méritos de Althusser al señalarlo, es que para que exista la explotación tiene que haber una serie de condiciones garantizadas. No se puede explotar, no se puede tener acumulación capitalista, si las condiciones para la producción capitalista no están dadas. Desde este punto de vista, no tiene mucho sentido pensar en jerarquías (entre producción y reproducción) sino que lo que hay que hacer es pensar en una totalidad contradictoria, una totalidad contradictoria dinámica. Marx muchas veces habla, en el volumen 2, del capitalismo como una totalidad contradictoria. Entonces, es más productivo pensar en términos de totalidad y de las distintas relaciones que constituyen esta totalidad y los tipos de vínculos existentes entre las relaciones que constituyen la totalidad.

Desde este punto de vista, es un hecho que es necesaria la reproducción de la fuerza de trabajo para que pueda haber explotación. Pero esto no implica una jerarquía: el corazón del capitalismo sigue siendo la extracción de plusvalor, pero esta extracción no puede llevarse a cabo sin que haya, primero, un trabajo de reproducción social que permita que las trabajadoras trabajen. En segundo lugar, dijimos que la TRS es también una teoria de la subjetivación en el sentido de que permite comprender la conformación, el moldeamiento de cierto tipo de subjetividad, porque la trabajadora que es explotada no es una "trabajadora abstracta". Esa trabajadora abstracta es lo que encontramos en el volumen 1 de El capital, donde Marx introduce el concepto de valor y de plusvalor. Ahí no sabemos nada de esa trabajadora, no sabemos el género, no sabemos la raza, qué tipo de trabajo realiza, no sabemos nada de eso porque Marx está moviéndose a un nivel de abstracción que le sirve para explicar cómo se produce el valor y como se extrae el plusvalor, sin mayores determinaciones.

Pero las trabajadoras no son entes abstractos, las trabajadoras son seres humanos, lo que significa que tienen cuerpos que son concretos, que tienen sentimientos y pensamientos específicos determinados por procesos históricos, ellas necesitan ser disciplinadas para trabajar, y esta disciplina afecta directamente el proceso productivo. Entonces, en 
el momento en que miramos el proceso productivo (por ejemplo, en el capítulo dedicado a la jornada de trabajo en El capital), ya encontramos una trabajadora menos abstracta de la que encontramos en otros capítulos. Por ejemplo, si leemos los capítulos sobre la maquinaria, ya encontramos que lo que está en juego no es solamente un proceso de extracción de valor sino también un proceso de dominación, de opresión, a través de la maquinaria. A mí me gusta usar la formulación de Daniel Bensaïd sobre el capitalismo como una totalidad contradictoria de relaciones de explotación, alienación y dominación (es decir, opresión). En última instancia, el capitalismo es estas tres cosas en una. No hay jerarquía entre ellas, no es útil hablar en términos de jerarquías porque estos tres elementos son co-constitutivos y trabajan juntos para que el capitalismo exista.

Por esta misma razón, cuando hablamos de clase, porque esta es la preocupación subyacente en este debate, creo que es totalmente improcedente pensar en la clase haciendo foco exclusivamente en la explotación. ¿Por qué? Porque como dije, las clases están compuestas de personas históricas concretas para quienes la explotación también se lleva a cabo en formas concretas que incluyen formas específicas de disciplina y opresión. Por ejemplo, pensemos en el acoso sexual en el lugar de trabajo: ¿cómo debemos pensar este fenómeno? Yo creo que este fenómeno es parte de la forma en que el proceso de trabajo funciona y se organiza en los lugares de trabajo. Si pensamos en el ejemplo de las maquiladoras, donde una encuentra siempre una masa de trabajo feminizada, la violencia sexual no es simplemente un fenómeno cultural, ideológico, interpersonal, es una forma de disciplinamiento de la fuerza de trabajo, es una forma en la que la explotación es vivida por estas trabajadoras en el lugar de trabajo e incluso fuera de él. Si pensamos en el caso de las trabajadoras agrícolas migrantes en Europa, por ejemplo en Sicilia o España, que trabajan en condiciones de semi esclavitud, encontramos que la violencia y el abuso sexual en las plantaciones es la experiencia cotidiana de explotación de estas trabajadoras, es la forma de disciplinarlas, de aterrorizarlas, de ponerlas en condiciones en las que no tienen otra alternativa que quedarse allí. Entonces, cuando tenemos una mirada reducida de la clase a lo que pasa en la producción, como si se tratara sólo de las condiciones laborales y del problema del salario, nos estamos perdiendo mucho de lo que hace a la experiencia concreta de la trabajadora como tal. Porque, como muestran estos casos, no podemos separar la opresión sexual de la explotación: la opresión sexual es el modo en el que se garantiza la explotación de estas trabajadoras.

Tithi Bhattacharya. Quisiera agregar algo a esto que dijo Cinzia: 
pretender entender el sistema capitalista en su conjunto mirando sólo cómo se extrae el plusvalor, es como querer entender al ser humano mirando sólo cómo late su corazón. Una ecografia del corazón puede decirme muy poco sobre alguien: en todo caso puede indicarme que el corazón está andando bien (y el corazón es el órgano vital del cuerpo), pero no puedo decir nada sobre la persona. De manera análoga, la producción de valor y la extracción del plusvalor vía explotación es la parte latiente del sistema, pero limitándonos a mirar eso entenderemos poco acerca del sistema en su conjunto. Dicho esto, quisiera volver al tema de las jerarquías entre producción y reproducción. Lo que debemos tener siempre en mente es que, pese a que puede no haber una jerarquía en términos políticos, sin embargo, la extracción de plusvalor y el proceso de acumulación tienen efectos condicionantes sobre el sistema en su conjunto. El proceso de trabajo, el modo en que es extraído el plusvalor, la cantidad de plusvalor que se extrae, todos esos factores tienen efectos condicionantes sobre el sistema en su conjunto. Determinan la duración de la jornada laboral, determinan qué tipo de luchas son necesarias; si la tasa de ganancia cae, determina qué servicios sociales se recortan, etc. Eso no significa que el capital tiene control directo sobre la esfera reproductiva pero sí significa que la acumulación de capital tiene efectos condicionantes en el conjunto del sistema. Por ejemplo, una puede decir que en su tiempo libre no tiene que explicarle a ningún jefe qué es lo que hace en su jardín, cómo trabaja allí o qué es lo que planta, debido a que es un tiempo "libre de capitalismo". Pero no es verdad, porque el capitalismo determina cuándo una puede realizar ese trabajo: de hecho, determina exactamente cuáles son los dias en que una puede hacer ese trabajo y en qué horarios puede hacerlo, porque depende de la duración de la jornada de trabajo, de la estructura de la familia, las cuales son partes de la realidad social del capitalismo. Entonces, el trabajo asalariado, el proceso de trabajo y el proceso de acumulación tienen efectos condicionantes sobre el sistema como un todo. No determinan sólo la esfera de la producción sino también el Estado, y el modo en que el Estado impone leyes y reglas a la población. Por ende, la mejor forma de comprender la relación entre la esfera de producción y la de la reproducción es en términos de estos efectos condicionantes que tiene la producción en el conjunto de las relaciones sociales del sistema capitalista, en lugar de pensarlas en términos del predominio de una sobre la otra o pensar si una es "mejor" que la otra.

\section{¿Qué produce el trabajo doméstico? Una discusión sobre el valor en el capitalismo}

Cinzia Arruzza. Vinculado con esta discusión de la relación entre 
producción y reproducción, existen dos tendencias diferenciadas de la TRS. Una se origina en el operaismo italiano, de la mano de feministas obreristas como Mariarosa Dalla Costa, Selma James, Leopoldina Fortunati, Silvia Federici. La otra se sitúa en el contexto angloamericano, particularmente en Canadá ${ }^{7}$ pero también en Estados Unidos. Hay varios elementos en común entre estas dos perspectivas que utilizan la reproducción social como lente fundamental. Pero también existe una distinción sustancial entre ambas que tiene que ver con si se considera que el trabajo doméstico produce valor [de cambio] o no.

En la tradición obrerista (y esto también está conectado con el modo en que la tradición obrerista italiana empezó a pensar que el valor es producido socialmente por fuera del lugar de trabajo, es decir generado socialmente, basándose en cierta lectura de fragmentos de los Grundrisse de Marx) la consideración fue que el trabajo doméstico produce valor de cambio. La idea es que el capitalista y el trabajador varón firman un contrato que ya incluye el plusvalor generado por las mujeres en el hogar, por el ama de casa. Esto implica, en cierto sentido, que existe una suerte de contrato sexual. ¿Por qué las obreristas italianas pensaron de este modo? Porque consideraban que, dado que la fuerza de trabajo es una mercancía y dado que la reproducción social produce fuerza de trabajo, por ende la producción de esa mercancía implica la producción de valor. Conclusión: el trabajo doméstico produce valor [de cambio].

La otra tradición insiste en que el trabajo doméstico no produce valor [de cambio] sino que simplemente, y de modo crucial, produce las condiciones para la producción de valor a través de la regeneración de la fuerza de trabajo y de la trabajadora que la porta. ¿Dónde reside la diferencia? El punto está en el modo en que entendemos el valor. El valor es la expresión de una relación social: hay producción de valor cuando hay generación de capital en el contexto del trabajo organizado en términos capitalistas. La generación de valor no tiene que ver con la producción de cosas, de valores de uso. Yo puedo producir la misma cosa que, en un caso, será una cosa útil (un valor de uso) y también un valor de cambio; y, en otro caso, será sólo una cosa útil (y no un valor de cambio).

7. En 1969, la canadiense Margaret Benston publica el artículo "The Political Economy of Women Liberation" en la revista marxista Monthly Review. Alli desarrolla la idea de que el trabajo (no pago) de las mujeres en el hogar es un proceso de producción (no de consumo) esencial para la acumulación capitalista. Sin embargo, Benston aclara que este carácter esencial no implica que dicho trabajo produzca valor debido a que no se realiza para el mercado, sino que las amas de casa producen valores de uso que son consumidos en el ámbito privado del hogar. Para un recorrido sobre los distintos abordajes acerca del trabajo doméstico como productor de valores de cambio o valores de uso, véase Ferguson (2020). 
La cuestión reside en la imposibilidad de aplicar la noción de trabajo socialmente necesario al trabajo doméstico. ¿Por qué? Precisamente porque el trabajo doméstico, como dijo Tithi, no está organizado ni de forma industrial ni de forma capitalista. Sufre el impacto del capitalismo, e incluso utiliza los productos del trabajo industrial (como los lavarropas, lavaplatos, aspiradoras), pero en sí mismo no está organizado en términos capitalistas, motivo por el cual no hay forma de que se vuelva trabajo abstracto. En los hechos no existe la organización social que permita hablar de generación de valor [de cambio] del trabajo doméstico.

Desde mi punto de vista, la posición obrerista estuvo basada en dos ideas. Ya expliqué la idea racional: dado que producimos una mercancia (fuerza de trabajo), entonces estamos produciendo valor. El razonamiento subyacente era la tendencia creciente en el operaismo italiano a pensar que, con el capitalismo avanzado, el valor ya no se producía solo en el lugar de trabajo sino que se producía en todas las relaciones sociales (la noción de "obrero social" de Negri, etc.). El segundo elemento en el que se basa la consideración de que el trabajo doméstico produce valor era una preocupación. En resumen la idea era: "si encontramos el modo de demostrar que las amas de casa son trabajadoras productivas, entonces podemos demostrar que son parte de la clase obrera y que deberian ser sujetos centrales de la lucha". Sobre el primer punto, creo que Negri se equivocó: no me convence su lectura de los Grundrisse, creo que no funciona, pero no tenemos el tiempo para discutirlo en este mini curso. Sobre el segundo punto, comprendo perfectamente la preocupación pero una preocupación no es una base suficientemente sólida para una teoría.

Mi respuesta sería: debemos desafiar la idea de que el sujeto de la revolución son solo los trabajadores productivos. Marx nunca escribió eso. ¿Dónde está escrito eso? Marx nunca dijo que solamente los trabajadores productivos eran la clase obrera o que solamente los trabajadores productivos eran los sujetos revolucionarios. En sus escritos politicos, intenta encontrar subjetividad potencialmente revolucionaria en distintos lugares, incluidos los esclavos en la Guerra Civil norteamericana, o los campesinos rusos que defienden el $\mathrm{mir}^{8}{ }^{8}$ etc. Entonces, es un error categorial pensar que la distinción entre trabajadores productivos y trabajadores improductivos tiene un significado político. Esa distinción no debería interpretarse como "quienes son de la clase obrera revolucionaria y quienes vienen detrás". Esa distinción

8. Comunidad rural rusa en la que las tierras eran colectivas y regía la asignación familiar de parcelas para el cultivo. 
es importante para el análisis de la acumulación capitalista y de cómo funciona el capitalismo.

En los Grundrisse, Marx escribe explicitamente que el trabajo improductivo, las actividades del trabajador improductivo, son absolutamente cruciales para la vida del capitalismo. Sin ese trabajo el capitalismo no funciona. Desafortunadamente, no menciona el trabajo doméstico. Probablemente tenía en mente, por ejemplo, el trabajo de ventas, de servicios, etc., que no producen directamente una mercancía pero sin el cual es imposible la realización del valor dado que las mercancías no podrían venderse sin él. Personalmente considero que es importante mantener la distinción entre trabajo productivo e improductivo porque nos brinda herramientas desde el punto de vista del análisis de las dinámicas capitalistas. Si quiero entender las crisis, necesito saber dónde se produce valor, cuáles son los sectores, etc. Pero eso no es una teoría política. Quiero preservar la distinción porque es útil analíticamente siempre teniendo cuidado de no confundirnos y considerar que esa distinción es la base de una teoría política sobre el sujeto revolucionario. No era así para Marx y no debería ser así para nosotras. Este punto de vista me permite no tener la preocupación (que tenian las operaistas italianas) de decir que el trabajo doméstico produce valor. Alcanza con decir que produce las condiciones de posibilidad para que el capitalismo exista y también para que existamos los y las trabajadoras.

Para finalizar, y en modo un poco esquemático, me gustaría senalar las tres principales formas en que el trabajo de reproducción social puede ser organizado de forma asalariada. Puede ser un trabajo asalariado pero en sectores no productivos, por ejemplo el trabajo en sectores públicos como docentes, enfermeras, trabajadoras de limpieza en sectores públicos, etc. Puede ser un trabajo asalariado en servicios personales, por ejemplo, empleadas domésticas o personal de cuidado en casas particulares. Este es un trabajo que no produce valor (o sea, no hay generación de nuevo valor o plusvalor), aunque por supuesto que hay explotación. Y, por último, puede ser un trabajo asalariado de reproducción social que sí produce valor, por ejemplo las trabajadoras de McDonald's, las mozas, las cocineras, las enfermeras en clinicas privadas: todas ellas están produciendo una buena cantidad de valor. Este sí es trabajo reproductivo que, al mismo tiempo, es trabajo productivo en el sentido de la producción de valor bajo el capitalismo.

Tithi Bhattacharya. Quisiera agregar una cosa. No creo que tengamos que dar una pelea para que el trabajo doméstico sea considerado productivo desde el punto de vista del capital. ¡Es malo ser productivo para el capital! No es algo por lo que sea bueno esforzarse. Realmente no me imagino la escena dentro de la unidad familiar en la que di- 
gamos: "¿Estoy limpiando en la misma cantidad de tiempo en que lo hace Cinzia? ¿Qué parte de mi casa he limpiado en comparación con lo que ha limpiado Cinzia?" No creo que eso sea algo bueno para las familias. No miremos la producción de valores de uso exigiendo que sean reconocidos como valores de cambio. Eso es algo imposible. Lo que sí podemos exigir es que el trabajo doméstico sea evacuado del ámbito privado y que se haga público, del mismo modo en que lo es el servicio de salud. Nadie administra las vacunas en el seno del hogar sino que son administradas en el espacio público. De forma similar, no tiene sentido que en una misma cuadra, en los Estados Unidos, haya 10 cortadoras de pasto, una para cada hogar individual. O que haya cocinas privadas. Hasta donde sé, en la actualidad ya existen las cocinas públicas para los ricos: se llaman restaurantes. Lo que nosotras queremos es que cocinar sea una opción. A veces, si te invito a mi casa, puedo querer hacerte una comida, pero lo que no quiero es cocinar todos los días para que podamos alimentarnos mis seres queridos y yo. Lo que necesito son cocinas públicas en mi calle, en las que pueda trabajar junto a mis vecinas o vecinos, amigos, compañeras o compañeros, y que compartamos la tarea de cocinar la comida. Eso es mucho más eficiente que la actual organización del trabajo doméstico y de nuestras vidas.

\section{La familia, la reproducción social y el capitalismo}

Tithi Bhattacharya. Voy a comenzar con la cuestión de si el capitalismo puede sobrevivir sin la familia. La respuesta corta es no. Es una respuesta corta pero tiene una explicación larga: cuando pensamos en cómo salvar al planeta, abolir los combustibles fósiles o terminar con las empresas de deforestación, pensamos en qué tipo de movimientos de masas necesitamos para frenar a estas industrias, ¿verdad? Bien, para sacarnos de encima a la familia vamos a necesitar un movimiento de masas mucho más fuerte aún. Se necesita mil veces más fuerza para luchar contra la "ideologia de la familia" porque es una institución muy estable, en cierta medida porque el capitalismo se beneficia de una "historia previa" de la familia, de modo tal que crea la impresión de que la familia es parte de la historia de la humanidad desde la época de las cavernas. Es una mitología que el capitalismo utiliza apoyándose en un hecho insoslayable que es que la familia tiene una existencia previa, pese a que haya adoptado formas muy diferentes a como la conocemos actualmente. Esto le ha dado al capitalismo una suerte de "beneficio histórico-ideológico" para decir: "la familia es eterna, sólo los comunistas quieren abolirla". E históricamente, el capitalismo ha encontrado en la familia un lugar confiable para la reproducción de la fuerza de 
trabajo. "Confiable" es un adjetivo importante aquí porque la "forma familia" no emergió de modo pleno en el comienzo del capitalismo: por el contrario, fue el resultado de un proceso de prueba y error a partir del cual el capitalismo encontró una unidad de reproducción confiable.

De alli que el capitalismo permita cierto margen de variaciones para la "forma familia", pero la familia burguesa heteronormativa es siempre el horizonte de unidad familiar que tiene el capitalismo porque es la forma más confiable y más barata de reproducir la fuerza de trabajo, y también de reproducir los propios valores e ideología acerca de la familia. Hoy tenemos que estar agradecidas al movimiento LGBT y sus versiones alternativas de familia (y espero que eso continúe) pero, como es evidente, eso no liquida la homofobia y tampoco la transfobia. Y la razón por la que el horizonte de heteronormatividad continúa existiendo es porque la familia heteronormativa sigue siendo la unidad más confiable y barata para la reproducción en el capitalismo. Poner el foco allí, como lo hace la Teoría de la Reproducción Social, no es en absoluto un reduccionismo biológico porque, en el terreno de la teoría abstracta, no importa que sean las mujeres las que producen biológicamente a las futuras trabajadoras, lo que importa es que las niñas sean producidas (y reproducidas) de una forma confiable. La pregunta por el género y la sexualidad se introduce porque el capitalismo hace surgir el patrón heteronormativo en la medida en que éste le garantiza la reproducción de un modo más estable. Esa sería mi primera respuesta a la pregunta de si el capitalismo puede sobrevivir sin la familia.

La segunda cuestión que quisiera enfatizar aquí es que todas nosotras vendemos nuestra fuerza de trabajo por un salario pero no lo hacemos por el salario, lo hacemos para vivir. Por ende, el problema de la vida y del mantenimiento de la vida adopta un lugar central. Del modo en que yo lo veo, bajo el capitalismo está el sujeto y están los medios para la reproducción de ese sujeto: comida, ropa, abrigo, etc. Entre el sujeto y esos recursos para la reproducción interviene el salario. El salario es un medio para que el sujeto obtenga esos recursos. El salario es, también, lo que separa al sujeto de esos recursos. El problema de muchas luchas políticas es que se focalizan en el salario como si el único fin fuera el salario. Pero nosotras no estamos luchando solamente por el salario, nuestro foco debería ser que estamos luchando por la vida, que estamos luchando por la reproducción de nosotras mismas, por las formas en que estamos obligadas a conseguir los medios para reproducirnos a nosotras mismas. Por ende, las luchas sindicales que desprecian las cuestiones de aumento de la vivienda, etc. y se focalizan solamente en la cuestión salarial no comprenden que el salario es la forma en que nos ha sido alienado el acceso a los medios de vida. Como marxistas debemos comprender que es la carencia de medios 
para reproducirnos a nosotras mismas lo que nos hace perseguir un salario. Entonces, esa suerte de separación entre el sujeto y sus medios de reproducción (que hace que necesitemos el salario) debemos mantenerla siempre en mente en nuestras luchas politicas.

La tercera cuestión que quiero destacar es que Cinzia señaló algo muy importante respecto de la construcción de la subjetividad y quisiera aportar un ejemplo perturbador al respecto. Hay un libro muy bueno del historiador marxista Marcus Rediker llamado The Slave Ship (2007). $\mathrm{El}$ argumento central trata sobre un ser humano que es capturado en la costa africana. Antes de ser capturado era un ser humano libre que estaba jugando bajo el sol, o haciendo el amor o contando historias; llega a Virginia para trabajar en los campos de algodón y se transforma en un esclavo: ¿cómo es que este ser humano se transforma mágicamente en un esclavo? El barco esclavista, argumenta Marcus, es la fábrica que produce la esclavitud. Es en el barco donde una disciplina terriblemente coercitiva y punitiva es ejercida sobre el cuerpo de este ser humano para matar todo lo que tiene de espíritu libre y torturarlo de modo tal de someterlo a la lógica de la esclavitud. Cuando llega a las costas de Virginia para trabajar en la plantación, este ser humano ya es un esclavo y se vuelve más esclavo en función de torturas similares a las vividas en el barco. Es bastante perturbador leer el libro porque describe las muchas torturas que son realizadas a los esclavos en los barcos. Pero es un buen recordatorio de que nuestras subjetividades son creadas bajo el capitalismo. La esclavitud es el ejemplo más extremo pero tenemos que pensar, como dijo Cinzia, que no es natural para nosotras ni ser una trabajadora ni ser una mujer o un hombre o lo que sea, o ser una esclava. Todos esos son, simplemente, comportamientos no naturales que han sido producidos por una suerte de tortura sobre nuestros cuerpos y nuestras mentes y nuestros espíritus libres. Pero la lección que deberíamos sacar de "el barco esclavista", es que, pese al increíble nivel de tortura hubo revueltas de esclavos, los esclavos se organizaron colectivamente en estos barcos y pelearon. Por ende, lo que aprendemos es que no importa el nivel de la tortura y de la coerción ideológica que se ejerce bajo el capitalismo tanto en la esfera de la reproducción social como en la de la producción: las personas siguen organizándose colectivamente para desafiar ese orden.

Volviendo al tema de la familia y si ésta es eterna o puede ser abolida, nosotras sabemos que dentro de la familia, en general las mujeres llevamos adelante una cantidad desproporcionada de trabajo en relación con los varones. En Estados Unidos, de acuerdo a una encuesta cuantitativa, semanalmente los varones realizan nueve horas menos de trabajo doméstico que las mujeres, o sea, que las mujeres realizan nueve horas más de trabajo doméstico que los hombres. Nueve horas 
es un montón de tiempo. Y esto es Estados Unidos, en muchos otros países, como por ejemplo mi país, India, esa distancia es mayor y acá me dicen que en Brasil también. Eso es así porque, por ejemplo, en buena parte de mi país no hay agua corriente, por ende, las mujeres tienen que caminar millas para conseguir agua, lo cual incrementa las horas de trabajo doméstico.

Decíamos antes que la familia es muy importante como forma confiable de reproducción de la fuerza de trabajo, y que el capitalismo llegó a esta forma a través de prueba y error, tuvo que hacer cierta experimentación con la "forma familia" cuando surgió la producción masiva (la industria). Les pregunto a ustedes: ¿cuál sería la forma ideal para el capitalismo en el surgimiento de la gran industria? ¿Que la mujer trabaje o que la mujer se quede en el hogar? Lo que efectivamente vemos en los primeros momentos de la industrialización es que el capital no se preocupó por la familia en absoluto. Y fue así porque el capital no advirtió cuán útil era la familia, lo único que le preocupaba era que todo el mundo trabajara lo máximo posible: mujeres, niños, varones, todo el mundo trabajando en las fábricas todo el tiempo.

Cuando hago talleres sobre TRS, siempre digo que el complemento perfecto del volumen 1 de El capital, para entender la Teoría de la Reproducción Social, es La situación de la clase obrera en Inglaterra, porque es una ilustración de lo que es la reproducción social en términos históricos. Esos dos libros se complementan muy bien. ¿Qué pasa cuando todo el mundo en la familia trabaja todo el tiempo en la fábrica? Esa es la situación en los primeros momentos del capitalismo. Todo miembro de la familia era empleado para trabajar, incluso niñas de seis años de edad, durante 12 horas por día. Voy a leerles un ejemplo:

Sobre la causa de la muerte de Ann Galway, de 45 años de edad, el 16 de noviembre de 1843, los periódicos describieron la vivienda de la difunta en estos términos: vivía en el núm. 3 de White Lion Court, Bermondsey Street, Londres, con su marido y su hijo de 19 años, en una pequeña habitación donde no había ni cama, ni sábanas ni mueble alguno. Ella yacía muerta al lado de su hijo sobre un montón de plumas, esparcidas sobre su cuerpo casi desnudo, pues no había allí ni frazada ni sábanas. Las plumas se pegaban de tal modo a su cuerpo, que hubo que limpiar el cadáver para que el médico pudiera examinarlo; él lo halló totalmente descarnado y lleno de parásitos. En el piso de la pieza había un hoyo que servía de retrete a la familia. (Engels, 1845, p. 74)

Esta era la vida normal de las trabajadoras inglesas. Entonces, piensen en la vida de Ann Galway que, obviamente, era una trabaja- 
dora irlandesa. Piensen en su vida y luego compárenla con la vida del empresario que la hizo trabajar hasta la muerte. ¿De dónde venía su dinero? Primero, de la fábrica; pero en segundo lugar venía de la producción algodonera que estaba desarrollándose en Virginia en la que el empresario tenía acciones. ¿Y quién trabaja en las plantaciones de algodón? Gente traída de su tierra en África. Es decir que hay dinero de la esclavitud mezclado en este asunto. Y en tercer lugar: ¿dónde se vendía el algodón? Se vendía a gente en India. Lo que vemos son tres conexiones que construyen la savia del capital: la figura moribunda de la trabajadora irlandesa, la figura moribunda del esclavo y la figura moribunda del sujeto colonial desposeído. Estos son los tres momentos violentos que construyen el imperio forjado por el capital. Recuerden que en estos tres casos, la familia del esclavo, la familia colonial y la familia de los trabajadores campesinos fueron devastadas por el capital para que el capital experimentara con la "forma familia". Estas son las sangrientas y violentas formas en las que el capital hizo experimentos sobre cómo funciona la familia.

Pero si la clase obrera, como Ann Galway, termina muriendo, se transforma en un problema muy grave para el capital, porque se queda sin trabajadores. Si todos mueren: ¿cómo podría producirse la ganancia? Entonces, ¿quién tiene que intervenir? El Estado capitalista. Un amigo mio, que es comediante, tiene una forma muy graciosa de describir la relación que existía en ese período entre el capital industrial y el Estado capitalista. Dice que el capital industrial es como un bebé en un carrito de supermercado paseando por las góndolas y diciendo: "quiero, quiero" y el Estado capitalista es el padre que va empujando el carro y diciendo "¡No, no, no! ¡No podes llevarte todo eso porque si lo hacés no va a ser bueno para ninguno de los dos!". Es el tipo de metáfora ilustrativa de la relación entre capital industrial y Estado capitalista.

Lo cierto es que, en función de la salud del sistema en su conjunto, el Estado capitalista tiene que salir al rescate de la familia, porque el capital industrial está metiendo a toda la clase obrera dentro del proceso de producción y destruyendo la reproducción de la fuerza de trabajo. Entonces el Estado capitalista crea legislación para salvar a las familias obreras. Las primeras leyes fueron para limitar el trabajo infantil de modo que las mujeres y los niños no pudieran trabajar más en las fábricas; en 1847 se aprueba la jornada de 10 horas. En 1842 se aprueba la legislación sobre el trabajo en las minas y las mujeres no pueden ingresar más a trabajar dentro de las minas porque son "criaturas tan frágiles" que ya no deben ingresar a trabajar allí. Entre 1833 y 1874 hay muchas leyes industriales para reducir las horas de trabajo, etc. Y, a mi juicio, el capítulo más hermoso del volumen 1 de 
El capital es el que Marx dedica a la jornada de trabajo, capitulo que debería leerse al unísono con el libro de Engels.

Todas estas medidas legislativas vinieron junto con nuevas nociones de domesticidad: si vos sacás a las mujeres de la fuerza de trabajo para construir esa nueva cosa llamada "familia", también hace falta construir ciertas ideas de domesticidad que muestren como algo "antinatural" que las mujeres sean parte de la fuerza de trabajo. Por ejemplo, con la legislación del trabajo en las minas de 1842, se estableció que las mujeres no debian usar pantalones (obviamente las mujeres usaban pantalones todo el tiempo trabajando en las minas). Pero a partir de aquí las mujeres debian usar "ropa de mujeres". Las ideas de familia, de domesticidad, del rol de las esposas, todo eso surgió en esta época para reafirmar la familia obrera, para salvar a la familia obrera y también para crear nuevos y muy estables roles de género con el objetivo de colocar a esa familia en la posición de reproducción de la fuerza de trabajo. El género juega un rol constitutivo en el proceso de producción como un presupuesto de ese proceso de producción.

Quisiera referirme brevemente a la cuestión de la familia esclava y su importancia para la TRS. Hay dos libros que son obviamente cruciales en la formación de mi pensamiento al respecto. El primero es el de Angela Davis y el otro el de Dorothy Roberts, cuyo título es Killing the Black Body. El segundo capitulo de este libro, "On the Slave Family", trata sobre las formas en que la familia esclava fue estructurada, torturada y degradada en las plantaciones esclavistas. ${ }^{9}$ ¿Cuál es la importancia de la familia esclava para la TRS, desde mi punto de vista? Como hemos dicho, Marx se equivoca cuando dice que el capital deja la reproducción de la fuerza de trabajo en manos del trabajador, porque lo cierto es que los trabajadores no se reproducen del modo en que quieren sino que reproducen la familia de acuerdo a ciertas relaciones sociales en las que la familia está inserta. Por ejemplo, si yo quisiera reproducir mi fuerza de trabajo aquí en Brasil y para hacerlo quisiera abolir la monogamia, no podría hacerlo, porque no puedo decidir las condiciones de mi propia reproducción. Pensar que sí puedo decidirlas es una mirada voluntarista porque la familia no está librada a sus propios mecanismos de reproducción.

Sin embargo, sí tiene una relativa autonomía si la comparamos con el lugar de trabajo. Como dijimos antes, el ritmo del capital no es tan directo en la esfera de la reproducción social como lo es en el de la producción de mercancías. No hay ningún jefe que venga a decirte exactamente qué hacer con la familia en el día a día. Eso no significa que el espacio de la familia sea autónomo, pero es más autónomo que

9. Véase Roberts (1997). 
el lugar de trabajo. Eso es así, excepto en el caso de la familia esclava. Por eso es importante pensar la familia esclava desde la TRS. La familia esclava es un ejemplo de intervención directa del capital en la esfera de la reproducción y trata de moldearla en forma directa. Y la razón por la que hace esto es muy simple, puntual y funcional. Primero, porque el capital podía permitirse que los esclavos se murieran porque podía conseguir nuevos esclavos. Pero después se frenó el comercio de esclavos cuando fue abolida la esclavitud y los capitalistas ya no podian ir a Ghana a buscar nuevos esclavos cuando éstos se morian, entonces tenían que producirlos ellos mismos, del mismo modo que producian algodón. Como probablemente recordarán en la descripción de Angela Davis y también en el libro de Dorothy Roberts, esto implicó las distintas formas inhumanas en las que el esclavo varón era introducido en un grupo con una esclava mujer y era obligado a procrear. Las mujeres esclavas eran violadas para lograr la reproducción de los esclavos. E1 control directo de la reproducción en la familia esclava es una forma de reproducción social bastante única en el capitalismo, en la que el capital interviene de modo directo y regula la reproducción de manera violenta.

Por último quisiera referirme a la migración, porque la migración es otra forma en que el capital regula la reproducción de la fuerza de trabajo. Por ejemplo, esto se observa claramente en el caso de Estados Unidos y la inmigración mexicana. Estados Unidos no tiene que pagar por la educación y menos aún por la salud de los trabajadores mexicanos y, sin embargo, dispone de su fuerza de trabajo para producir. La reproducción social de esos trabajadores es gratuita y su salario es sumamente bajo. Es vital para el capital que el monto de dinero invertido en la reproducción de la fuerza de trabajo sea siempre el mínimo posible: siempre necesita recortar costos y siempre recortará costos del modo que sea en la esfera de la reproducción social. Entonces, de repente te quitan el sistema de salud, de repente te quitan las escuelas, te quitan el agua. Esos fueron los recortes en el período neoliberal y, como dijo Cinzia, fue el modo en que el capital atacó los medios a través de los cuales la reproducción social se había socializado bajo el capitalismo. Y es por eso que las luchas contra el neoliberalismo se concentran en esas esferas. Las primeras luchas han sido por proteger el agua, proteger la salud pública, proteger la educación pública, porque en 40 años de neoliberalismo esas esferas han sido atacadas.

\section{Los ataques a los derechos reproductivos y la crisis capitalista}

Tithi Bhattacharya. Me gustaría referirme a los ataques a los derechos reproductivos. ¿Por qué existen estos ataques a nivel mundial? 
Creo que la TRS puede apuntar ciertas condiciones de posibilidad para explicar esos ataques. Y una de esas condiciones es que, en períodos de crisis capitalista, es decir en tiempos de crisis de acumulación y ganancias, el capital tratará de moldear y cambiar tanto la esfera de la producción como la de la reproducción. De allí que, en esos períodos, debamos esperar nuevas formas ideológicas, nuevos ataques, nuevos inventos del capital. Estamos hablando de tendencias y condiciones de posibilidad, lo que no significa que podamos decir puntualmente el modo en que esto se va a manifestar en Estados Unidos, en Italia, en India o en El Salvador. Pero lo que sí podemos decir es que, en períodos de crisis, el capital va a tratar de reformar la esfera de trabajo y la esfera doméstica para restituir su ganancia.

Una de las formas de este tipo de reforma es el proyecto neoliberal: "queremos a todas las familias de todos los colores, siempre y cuando sean familias". Este proyecto tiene una fuerte ideologia familiar, todo el mundo está casado, tiene sus anillos, sus vacaciones familiares, etc. Toda la parafernalia de la familia heteronormativa es impuesta a la familia queer. Siempre que se sigan las prácticas, los ritos y todas las cosas sin sentido de la familia heteronormativa, la familia queer será aceptada. Otra variante de reforma es volver a lo que los historiadores marxistas han denominado la "invención de la tradición". No existe nada llamado "tradición", es completamente falsa esa idea. La tradición es reinventada para que encaje en el momento actual. Por ejemplo, en la actualidad en India todo el mundo está siendo forzado a encajar en el modelo de "familia hindú", cuando no existe tal cosa como una tradición de "familia hindú" previa al colonialismo. Es una invención del colonialismo. ¿Qué es una familia hindú tradicional? Lo que dice esta ideología es: "se debe conformar una familia hindú tradicional, especialmente los musulmanes que, como todo el mundo sabe, tienen demasiados chicos, son pedófilos, les pegan a sus mujeres y se casan con muchas mujeres... Todo el mundo sabe esto sobre los musulmanes... Entonces, en oposición a esto, los musulmanes deben convertirse al modelo de familia hindú tradicional que es fantástico". En Estados Unidos, observamos un incremento del discurso del "American way of life", "make America great again", ¿cierto? Bien, lo que nadie dice es que en este "American way of life", la apple pie (tarta de manzana) es tan americana como los barcos de esclavos. Los barcos de esclavos y la tarta de manzana son una rúbrica americana como tantas otras cosas. Se supone que el "American way of life" es aquel en el que la mujer se ocupa de cuidar el hogar, pero los salarios de ambos (del varón y de la mujer) son tan bajos que en verdad las mujeres no pueden quedarse en la casa y ocuparse de las tareas del hogar porque ambos deben salir a trabajar por un salario mínimo. 
Hay otra cuestión en relación con los ataques a los derechos reproductivos. Creo que en Estados Unidos suele pensarse que la Iglesia Católica es la primera en atacar los derechos reproductivos, pero no es así. La Iglesia Católica en el siglo XIX fue, de facto, pro aborto, porque la creencia se basaba en este concepto tan especial de los católicos que es la "aceleración" ("quickening"), que es la idea de que durante un cierto número de semanas el embrión se desarrolla en el útero y, en un momento dado, existe esta aceleración y ese es el momento en que el embrión recibe un alma. ${ }^{10}$ Esta era una idea bastante común en la ideología cristiana, motivo por el cual la Iglesia decía que antes de ese momento una podía hacer lo que quisiera con el embrión, sencillamente porque no era un ser humano. Solo después de la "aceleración" se transformaba en ser humano, por lo que antes de ese momento la Iglesia no tenía nada para decir sobre el aborto. En Estados Unidos hay un elemento claramente malthusiano en el ataque a los derechos reproductivos: la idea de que la tasa poblacional está cayendo, motivo por el cual hay que asegurarse que las mujeres produzcan más y más bebes. Por cierto, no olvidemos que Stalin, cuando pensó que la tasa de natalidad de la Unión Soviética tenía que competir con los promedios mundiales, comenzó a ofrecer medallas a las mujeres que tuvieran más niños. La sociedad que fue la primera en establecer el derecho al aborto como parte de las reformas de la Revolución Rusa, bajo Stalin repartió medallas para premiar la maternidad.

Volviendo al inicio, creo que la TRS puede predecir tendencias porque tiene una visión de la totalidad del capitalismo y eso nos permite conectar estas tendencias a los momentos de crisis capitalista. Pero las formas de expresión de esa crisis van a variar según los países, motivo por el cual necesitamos investigaciones históricas serias que ilustren cómo opera el proceso en cada esfera particular. Una última cosa sobre la TRS y el aborto y los derechos reproductivos: el derecho a tener bebés es tan importante como el derecho al aborto, porque en varios estados de África las mujeres de color han sido esterilizadas de manera forzada y sin saberlo. La cuestión de la esterilización forzada debe ser de particular importancia para nosotras como feministas marxistas y como revolucionarias marxistas. Tenemos el derecho a producir bebés del mismo modo que el derecho a negarnos a producir bebés. Ambos derechos son igual de importantes.

La TRS es particularmente útil, creo, para debatir con el feminismo liberal que considera el derecho al aborto, simplemente, como un pro-

10. "Hasta que el feto no se aceleraba, es decir hasta que la madre no sentía movimiento, no adquiría alma, y el fin de un embarazo solo se consideraba aborto después de ese momento" (Wiesner-Hanks, 2001). 
blema del útero. Por supuesto que el aborto es un problema del útero de las mujeres y los cuerpos gestantes, motivo por el cual la decisión de abortar es patrimonio de esos cuerpos. En ese sentido es un problema de "elección": es mi elección individual si quiero tener una bebé o no tenerlo. Lo que la TRS introduce es la pregunta por las condiciones que son necesarias para que una mujer realice esa elección. Para decidir tener una bebé quiero tener un trabajo estable, que mi pareja tenga un trabajo estable, si es que tengo pareja. Quiero estar segura de que, una vez que nazca, mi hija tendrá acceso a la educación pública de forma gratuita, o al servicio de salud cuando lo necesite, e incluso que yo pueda tener un parto seguro. Para tener una bebé también exijo vivir en un barrio seguro en el que mi niño (si es varón) o el padre de mi niño (si es varón), no sea asesinado por la policía, demando esos derechos. Todos esos temas están intimamente relacionados con tener una bebé: el trabajo, el estatus migratorio, el barrio, la política de encarcelamiento policial, etc. Todo eso está conectado al momento en que una mujer decide tener un hijo o no tenerlo. Reducir la cuestión del aborto sólo al momento de la decisión es tergiversar y malinterpretar completamente la complejidad del proceso social que implica esa decisión. Como feministas de la reproducción social es nuestro deber mirar el cuadro completo que hace a la toma de decisión, en lugar de mirar la decisión en sí misma.

Cinzia Arruzza. Ciertamente, la TRS puede ayudarnos, en el nivel de la teoria, a pensar qué significa la justicia reproductiva. En otras palabras, la TRS es nuestra respuesta a los dos proyectos neoliberales de los que hablaba Tithi. Porque, por un lado, el problema del aborto ha sido enmarcado por las liberales progresistas como un problema de elección: las pro-choice vs. las pro-life. Pero pro-choice no dice nada de las condiciones sociales que hacen que la elección sea posible. Quienes apoyan la posición pro-choice en Estados Unidos pero no apoyan el sistema de salud universal, son pro-choice sólo de palabra, porque lo cierto es que ese tipo de posicionamiento está negando la posibilidad de elegir a la gran masa de mujeres para quienes la salud privada es imposible de pagar. Desde esta perspectiva, la TRS puede ayudarnos a comprender qué se necesita para tener justicia reproductiva, tanto para las mujeres que no quieren tener hijos o no quieren tenerlos en un momento determinado, como para aquellas que sí quieren hacerlo, que necesitan medios para la reproducción como el acceso a un sistema de salud adecuado y un parto seguro. Porque si no existe un sistema de salud público o si este sistema es de mala calidad, tampoco es posible llevar adelante un embarazo, o hacerlo significa poner en riesgo la vida. Muchas mujeres mueren en el parto o mueren durante el embarazo, 
etc. Desde mi punto de vista, la TRS puede ser útil para elaborar una perspectiva de qué es necesario para tener una justicia reproductiva que no sea racializada y que incluya, realmente, a las mujeres de la clase trabajadora pobre.

\section{La sexualidad desde el punto de vista de la reproducción social}

Cinzia Arruzza. Por un lado, el capitalismo ha creado las bases para la emergencia de la sexualidad como esfera específica (ese es un argumento de Foucault que conectó el surgimiento de la sexualidad como campo específico con el surgimiento del capitalismo). Entonces, es el capitalismo el que hace posible que la sexualidad emerja como campo social y, por ende, que las identidades sexuales se cristalicen en base a orientaciones sexuales. Esto no era así antes del capitalismo: es posible hablar de prácticas sexuales homoeróticas pero estas prácticas no eran la base de la definición de una identidad personal. En la antigua Atenas todos los hombres aristocráticos tenían relaciones homoeróticas con jóvenes, pero eso no definía su género ni su identidad personal. La definición y cristalización de identidades sexuales basadas en orientaciones sexuales es un fenómeno reciente y contemporáneo que se corresponde con el surgimiento del capitalismo industrial.

El argumento de Alan Sears ${ }^{11}$ es que en el capitalismo encontramos, por primera vez en la historia, las condiciones de emergencia de múltiples identidades sexuales y podemos decir lo mismo de las identidades de género. Y esto, por supuesto, puede crear la ilusión de libertad sexual, libertad de expresión o incluso de auto creación de nuestras identidades de género, que es básicamente el argumento de los apologistas del capitalismo como sistema que lleva a la autonomía y a la liberación individual. Esta ilusión va en sentido contrario a la consideración original de la teoría marxista sobre la relación entre capitalismo y sexualidad. Porque originalmente, si tomamos lo que plantean no sólo los socialistas sino gente como Wilhem Reich o incluso Marcuse, la comprensión general sobre la relación entre capitalismo y sexualidad era bajo el paradigma de la represión. En otras palabras, la idea de que el capitalismo tiene la necesidad de reprimir nuestra sexualidad porque, de otro modo, no nos volveríamos sujetos económicos. En términos esquemáticos, lo que Foucault llamó el paradigma de la represión.

Con el neoliberalismo, lo que hemos visto es que no es exactamente eso lo que sucede, sino que el modelo de la regulación de la sexualidad no es el único modelo compatible con el capitalismo. Lo que hemos

11. Véase Sears (2017). 
visto desde la década del 60 y especialmente con el neoliberalismo es, en primer lugar, una creciente visibilidad del sexo, el uso masivo del sexo y de la sexualización en las publicidades y en el discurso público. También la multiplicación de las identidades sexuales y, más recientemente, la fluidez del género (gender fluidity) y la multiplicación de las identidades de género. Entonces, el modelo represivo no fue el único modelo compatible para la relación entre sexualidad y capitalismo. De hecho, el capitalismo ha demostrado ser más flexible: puede adaptarse e incluso puede cooptar, puede transformar identidades de género en nuevas posibilidades de generación de ganancia. Por ejemplo, ahora tenemos la multiplicación de marcas de ropa cuyo target son las personas queer, o bares para queers, etc.

Lo que dice Alan Sears es que todo esto puede darnos la ilusión de haber conquistado cierta libertad o de que el capitalismo puede conducir a la liberación sexual, y que la homofobia es un remanente ideológico de un pasado patriarcal. Pero no es así. Y para entenderlo vamos a usar el mismo tipo de esquema que usó Marx para entender la doble libertad del trabajador. Por un lado, es absolutamente cierto que bajo el capitalismo, y debido a la acumulación originaria, los lazos feudales se disolvieron y las personas ya no estaban atadas a la tierra, a la familia patriarcal; podían moverse, viajar. Eso llevó a la revolución de los derechos individuales y es, por supuesto, una forma de progreso en cierto modo. Pero Marx dice que es un fenómeno tipo Janus, en el sentido de que el otro lado de esta libertad y de la emergencia del individuo libre que es dueño de su cuerpo (por ende el cuerpo me pertenece a mí misma y ya no al señor feudal o a la iglesia, y yo puedo disponer de mi cuerpo, puedo viajar, cambiar de empleador, etc.), es la libertad entendida como miseria. En otras palabras, la ausencia de medios de subsistencia, de producción y reproducción. Y, por ende, la absoluta dependencia debido a que yo necesito vender mi fuerza de trabajo para mantenerme viva.

El abordaje de Alan Sears aplica esta lógica también a la compresión del modo en que funciona la sexualidad bajo el capitalismo. Por un lado, tenemos, especialmente en las grandes metrópolis y las áreas urbanas, la posibilidad, la visibilidad, la multiplicación de identidades de género, que son, fundamentalmente, conquistas de duras luchas, no son un regalo del capitalismo. Sin embargo, en la medida en que la reproducción social (es decir, la forma en que la gente puede reproducirse a sí misma) aún está subordinada a la producción de ganancia y a las presiones y condicionantes del capitalismo, aparece la otra cara de la libertad que es, básicamente, la compulsión. Por ejemplo, hay un fenómeno antiguo que Peter Drucker llama "normalidad 
gay". ${ }^{12}$ En Estados Unidos ha habido un proceso de normalización de las personas gays, de reproducción de formas familiares que están, precisamente, dentro del mismo paradigma de las familias heteronormativas: el hogar, la familia con dos padres, hijos, es decir, el tipo de estilo de vida aceptado. La única diferencia es que los dos padres son del mismo sexo. Esto es así por presiones objetivas de la acumulación capitalista a la reproducción de este tipo de unidad familiar en tanto unidad que internaliza la necesidad de llevar a cabo el trabajo de reproducción social. Este fenómeno ha sido llamado "la emergencia de la normalidad gay". Al mismo tiempo, aquellos que no pueden hacerlo porque son pobres, son marginalizados. Observamos el aumento de la marginalización de, por ejemplo, las personas queer pobres que no pueden reproducir este tipo de vida familiar estandarizada. Esto es lo que Alan Sears tiene en mente: que para comprender la sexualidad bajo el capitalismo no podemos mirar solamente la esfera del cambio personal y del reconocimiento de derechos legales: también tenemos que entender la sexualidad bajo la esfera de la reproducción social y cómo ésta está sujeta a las presiones del capitalismo.

\section{Desposesión neoliberal y reproducción social}

Cinzia Arruzza. Hay un conjunto de teorias recientes que sostienen que existe un proceso continuo y actual de acumulación originaria, es decir que estamos viviendo un proceso de desposesión, separación de las personas de los medios de producción, de la tierra, y, por ende, un desplazamiento masivo de las personas hacia las ciudades, a las megalópolis. Al respecto yo acuerdo en que hay varios elementos en común entre lo que sucede hoy y el proceso de acumulación originaria, pero también existe una diferencia sustancial, que consiste en la creación de sobrepoblación obrera sobrante a nivel nacional. El fenómeno de desposesión, por ejemplo el extractivismo en la Amazonía en la actualidad, no está generando necesariamente nuevos proletarios en el sentido de nuevos trabajadores "libres" de vender su fuerza de trabajo en el mercado. Está creando una enorme masa de lo que, en términos de $E l$ capital, se llama superpoblación sobrante, es decir, una enorme masa de población que no tiene chance de volverse un trabajador asalariado, de ser absorbido por el mercado de trabajo formal capitalista.

Esta masa de superpoblación puede ser directamente exterminada (esos son los proyectos de exterminio) o puede, básicamente, incrementar el número de habitantes de las villas en las megalópolis, cuyo único modo de sobrevivir es, básicamente, a través de la economía informal.

12. Véase Drucker (2015). 
Y creo que esto es una diferencia significativa con el pasado. Y creo también que hemos llegado a un punto que supera lo que Marx denominó ejército industrial de reserva a nivel nacional. Porque el ejército industrial de reserva es una masa de desempleados que el capitalismo necesita para tirar a la baja el salario y que, en términos generales, sirve como mecanismo de control de la clase obrera. El ejército industrial de reserva implica la idea de gente que está en reserva para entrar al mercado de trabajo y volverse un trabajador asalariado. Pero de lo que estamos hablando ahora es de una población sobrante que no es un ejército industrial de reserva, sino que es una masa de personas que no va a entrar nunca al mercado de trabajo. Desde este punto de vista, hay un trabajo que la Teoria de la Reproducción Social, junto con otros, tiene que hacer para explicar este fenómeno de desposesión y creación de población obrera sobrante, y cómo funciona la reproducción social en estas poblaciones sobrantes, etc. En sintesis, creo que hay mucho trabajo por hacer sobre este tema y quizás los lentes de la Teoría de la Reproducción Social sean útiles para ello.

Tithi Bhattacharya. Quisiera referirme a esta idea de que hay "gente innecesaria". Hay un punto de verdad insoslayable en esa percepción de que hay gente innecesaria. En el Sur global se aplica a la gente indigente, en India o África se aplica a la gente de las comunidades forestales ("forest people") o de las comunidades tribales ("tribal people"), en Estados Unidos se aplica a las personas negras en general, hay un sentimiento en las comunidades negras de que todos somos descartables, de allí es que haya surgido una teoría en la izquierda, a la que yo no suscribo en absoluto pero entiendo de donde surge, que es el "afro pesimismo". La teoría es incorrecta desde mi punto de vista pero se entiende por qué surgió en ciertas comunidades negras para explicar lo que la gente percibe como un genocidio negro. En Brasil puede pensarse del mismo modo.

Tengo dos cosas que decir al respecto. Lo primero es que lo que estamos tratando de hacer con los lentes de la Teoría de la Reproducción Social es mirar el proceso dinámico de la relación entre la producción de personas y la producción de mercancías. No es un proceso estático. Hay ejemplos históricos de poblaciones enteras que han sido exterminadas. Cuando Europa conquistó el "nuevo mundo", poblaciones enteras fueron exterminadas por la conquista y por las enfermedades traídas de Europa. Entonces, en un sentido, es posible llamar a esas poblaciones "gente innecesaria" para los primeros inicios del capitalismo. Pero sería un error considerar que ese proceso histórico puede aplicarse a este momento de forma estática y considerar que el capitalismo está decidido a exterminar a la llamada "población innecesaria". En lugar 
de eso, lo que deberíamos considerar es que estamos ante un proceso dinámico en el cual el esfuerzo (del capital) es siempre en función de la acumulación, por lo que cualquier cosa o cualquier persona que se interponga en esa acumulación va a ser exterminada. Pero que, en un punto, el capital siempre va a necesitar la fuerza de trabajo y que ello implica necesitar a las personas.

Entonces, en ciertas situaciones el capital va a retroceder, como lo hizo en los orígenes del industrialismo de los que hablaba antes. Porque cuando el capital extermina a las comunidades forestales (" $f o-$ rest people") lo hace para construir una fábrica en la tierra de esas comunidades, por lo tanto, necesita gente para trabajar en esa fábrica. Entonces lo mejor que puede hacer es contratar a una parte de esa "población innecesaria" para que trabaje en esa fábrica. Ese proceso es parte de lo que está pasando. Y todo esto sucede con una rúbrica de intensa racialización que ayuda a mantener los salarios bajos y hacer que esos empleos aparezcan como si fueran un regalo que el capital está haciendo a esa comunidad, algo que deben agradecer porque "son negros, qué más pueden pedir". Esa rúbrica ideológica justifica todo el proceso que se lleva adelante. Lo que quiero remarcar es que no podemos considerar que hay una orientación absoluta hacia el exterminio de las poblaciones racializadas porque, para ser honesta, las tareas más importantes para el capitalismo son llevadas a cabo por gente de color. Por ende, el capitalismo no puede destruir ese capital, el capitalismo no puede permitirse liquidar todo el capital que constituye la gente de color. Pero la racialización ayuda a mantener a la población bajo control y ayuda también a aniquilarla cuando es necesario. Por ende, si una comunidad está luchando para preservar su territorio está perfectamente justificado traer soldados y dispararles. Si una comunidad está luchando por la preservación de un bosque, está perfectamente justificado traer a los militares y limpiar el territorio de manifestantes. Eso es lo primero que quiero decir para mirar el proceso de un modo dinámico en lugar de verlo en un modo estático.

Lo segundo refiere a David Harvey, de quien soy una gran admiradora. Pienso que una buena parte del trabajo que ha hecho encaja perfecto con la Teoría de la Reproducción Social. Hemos hecho presentaciones juntos. El punto en el que no acuerdo con Harvey es la teoría de la acumulación por desposesión. ${ }^{13}$ No es que esté en desacuerdo con eso como descripción de un fenómeno histórico, porque claramente hay una acumulación por desposesión que está llevándose a cabo en este momento. Por ende, en términos históricos, es una formulación perfecta, y él ha sido el primero en descubrirla, y eso es un desarrollo

13. Véase Harvey (2004), el capítulo IV: "La acumulación por desposesión". 
fantástico de su trabajo. El punto en que no acuerdo es que, según David, la acumulación por desposesión está volviéndose el motor de la acumulación capitalista. En eso no tengo acuerdo. Yo sigo pensando que la extracción de plusvalor es el principal motor de la acumulación capitalista. Ese es el punto en el que no acordamos: en el significado de la teoría más que en la teoría como una descripción de ciertas formas de acumulación capitalista.

\section{Debates al interior del feminismo: las materialistas francesas, la interseccionalidad, la apuesta por "los comunes" y la mirada autonomista}

Cinzia Arruzza: Se han formulado algunas preguntas que involucran otras teorias feministas con las que la TRS tiene algunos puntos en común y también diferencias. Quisiera referirme brevemente a eso. Respecto a las feministas materialistas francesas como Danièle Kergoa$\mathrm{t},{ }^{14}$ hay una serie de puntos comunes con la TRS que tienen que ver con el análisis de las relaciones entre la opresión de género, la explotación, el capitalismo, la raza, etc. Pero, al menos desde mi punto de vista, la diferencia está en la matriz de la teoría que está basada en lo que las feministas anglosajonas llaman "teorias del sistema dual", es decir, en la idea de que tenemos, por un lado, relaciones sexuales de explotación y, por otro, relaciones capitalistas de explotación. Y, en las versiones más recientes de las materialistas francesas, un tercer tipo de relaciones que son las relaciones raciales de explotación. Estos tres tipos de relaciones son co-constitutivos, trabajan juntos, se combinan, pero antes que nada son tres formas de explotación con lógica autónoma.

La TRS se para desde el punto de vista de una teoría unitaria. Si bien reconoce que el patriarcado fue un sistema de producción y reproducción en las sociedades agrarias, considera que ya no sucede lo mismo en las sociedades capitalistas. En otras palabras, las relaciones patriarcales están presentes en la sociedad capitalista pero no forman un sistema con lógica autónoma. Lo que la TRS trata de explicar es, precisamente, cuáles son los elementos propios de la acumulación capitalista que generan las condiciones para la opresión de género y, es más, para una forma especifica de opresión de género (sin recurrir a ideas sobre los deseos de los varones de dominar a las mujeres o a ideas de tipo biologicistas). Por supuesto que hay ciertas similitudes respecto del modo en que las mujeres eran oprimidas en las sociedades agrarias

14. En la década del 80 Danièle Kergoat revisa la relación entre la explotación de clase y la opresión de género redefiniendo la noción de división sexual del trabajo a partir de colocar en el centro el concepto de "relaciones sociales de sexo". Véase Hirata y Kergoat (1997) y Kergoat (2003). 
pero, sin lugar a dudas, el modo en que las mujeres son oprimidas en el capitalismo no es el mismo que el de las sociedades agrarias.

El fenómeno de la opresión de las mujeres excede el capitalismo pero fue completamente transformado por el capitalismo, y decir "transformado" no es lo mismo que decir "integrado". Fue transformado justamente por la necesidad de subordinar la reproducción social a la producción de valor, la producción de ganancia. Yo diría que esa es la diferencia teórica más grande con el feminismo materialista francés. En última instancia, a nivel teórico, la diferencia está relacionada con el poder explicativo que nosotras le damos a la producción de valor y a la acumulación de capital para explicar ciertas dinámicas históricas. En un sentido, somos marxistas heterodoxas, pero en otro sentido, somos marxistas muy ortodoxas en la medida en que realmente creemos que la acumulación de capital es el "corazón latiente" del capitalismo y es el lugar donde hay que mirar para ampliar la mirada. La acumulación tiene, para nosotras, un gran poder explicativo del conjunto de los fenómenos sociales.

Nuestra mirada sobre el capitalismo de conjunto, y el modo en que funciona, también tiene que ver con las diferencias entre la TRS y la interseccionalidad. Yo diría que hay muchos puntos en común y que la principal diferencia es que en la mirada de la interseccionalidad (que es muy plural en su interior) lo que falta es una teoría del capitalismo como tal, de cómo funciona, de cuál es la lógica del capitalismo y, por ende, de qué es lo que explica la intersección de varias formas de opresión.

Sobre las relaciones de "los comunes" 15 y su potencialidad creo que es importante señalar lo siguiente. Cuando hablamos de TRS, no deberíamos confundir las tendencias y los condicionantes, con los modelos y los mecanismos específicos. Me explico: como hemos dicho, no todos los aspectos de la vida están entera y directamente regulados por el capitalismo. Hay un montón de cosas que pasan en la esfera de las relaciones personales que están constreñidos por ciertos horizontes de posibilidad pero que también están definidos por nuestra interacción libre. No me refiero solo a lo que pasa en la familia, también en las comunidades de amistad que son repositorios de afectos, de relaciones no mercantilizadas y espacios de creación de lazos de solidaridad. Hay alli, sin lugar a dudas, un elemento de "comunalidad".

De todos modos, el problema es que todas estas relaciones se dan bajo condicionantes específicos determinados por el capitalismo, que

15. La idea de "los comunes" o de "lo común" o "comunitario" se ha extendido en algunos sectores feministas y hace referencia a la construcción de relaciones sociales alternativas al capitalismo para la producción de la vida. Para una definición, véase Caffentzis y Federici (2018). 
vuelve imposible desarrollar el potencial de estas "comunalidades" hasta el final, es decir, vuelve imposible que el potencial de estas relaciones libres y no mercantilizadas, relaciones de cuidado y de afecto, se despliegue. En segundo lugar, es importante marcar que estos elementos de "comunalidad" pueden jugar un rol fundamental en la dinámica de las luchas en términos de su sostenimiento: como durante la huelga de las docentes ${ }^{16}$ o como en el caso de las Panteras Negras que organizaban desayunos gratis, o los migrantes organizando foros de solidaridad para la reproducción social desde abajo en la frontera. Este tipo de iniciativas sostienen la lucha y la hacen posible. Sin embargo, todas estas formas de solidaridad en el ámbito de la reproducción social, en sí mismas, son incapaces de desafiar las relaciones sociales generales en las que luchamos por la supervivencia. Organizarse colectivamente con amigos y compañeros, las formas colectivas y autogestionadas de cuidado de niños o de adultos mayores, puede mejorar nuestras vidas, puede hacer que nuestras vidas sean menos miserables, pero de ningún modo van a desafiar al capitalismo y a las relaciones sociales capitalistas. Solamente garantizan la reproducción social que el capitalismo necesita pero de un modo alternativo al modo familiar estándar. Desde el punto de vista del capitalismo, el trabajo de reproducción social está hecho. Entonces, yo diría que lo que tenemos que entender es que la mutualidad, las formas autónomas de autogestionar la reproducción social, tienen que estar siempre conectadas a las luchas y a los conflictos que atacan en forma directa los intereses y las ganancias capitalistas. De otro modo, podremos hacer nuestra vida menos miserable pero no vamos a cambiar la situación general.

Por último, la TRS presenta, de hecho, algunas diferencias respecto de la teoría autonomista o posautonomista. Un ejemplo es la apreciación respecto de los espacios autónomos, los espacios comunitarios o autogestionados de la reproducción social, y la apuesta a su crecimiento, en detrimento de las demandas hacia el Estado. Desde mi punto de vista, el camino al que tenemos que apostar, por supuesto que no es la hostilidad hacia las formas autónomas, a las experiencias autogestionadas o comunitarias de la reproducción social, pero en términos generales la perspectiva debería ser la socialización de todo el trabajo de reproducción social. Que la sociedad como un todo se haga cargo de la reproducción social y que esto no sea más un problema privado, relegado a la familia o al modo en que puedas resolverlo a través del mercado. ¿Cómo hacer esto? Bajo el capitalismo, el Estado se vuelve parte de la lucha, cuánto es posible obtener del Estado es parte de la

16. Refiere a las huelgas docentes desarrolladas en diversos estados de Estados Unidos durante 2018. 
lucha; cuánto es posible arrancarle en términos de salud pública, de escuelas públicas, de cuidados públicos, es parte crucial de la lucha. En el Manifiesto por un feminismo del $99 \%,{ }^{17}$ señalamos una serie de demandas hacia el Estado. Por supuesto que ese no es el objetivo último de la lucha, no es el horizonte final. Pero es parte de la lucha actual, de la lucha en curso, entre la privatización de la reproducción y la lucha para forzar al capital a pagar por la reproducción. No es el horizonte final porque el horizonte final es terminar con el Estado y construir una socialización general de la reproducción social, y eso es a lo que tenemos que llegar de algún modo. Pero en este momento hay una lucha para frenar la privatización de la reproducción social y para forzar una mayor distribución que fortalezca a las mujeres y que cree las condiciones objetivas y subjetivas para ir más lejos.

Tithi Bhattacharya: Para terminar quisiera referirme a la pregunta acerca de por qué, luego de la Revolución Rusa del 1917, las mujeres seguían siendo responsables del trabajo de reproducción social. En primer lugar, hay que tener en cuenta que el periodo de experimentación en el terreno de la reproducción social fue durante los primeros años. Once países capitalistas atacaron de forma inmediata el Estado obrero, lo rodearon y comenzaron una guerra civil. El libro de Wendy Goldman ${ }^{18}$ es fantástico, allí se puede ver cómo en las escuelas públicas las maestras están luchando, no hay recursos, no hay papel y sin embargo, es un momento de una gran experiencia de aprendizaje a través de la lectura y del juego. Se puede ver cómo intentan poner en pie estas cocinas comunitarias pero no hay comida, porque los ejércitos capitalistas bloquearon la Unión Soviética. Entonces, lo primero es tener en cuenta todos estos condicionantes. Sin embargo, la pregunta sigue siendo válida: ¿por qué son las mujeres las que principalmente llevan estas tareas adelante? En primer lugar, porque es un periodo de transición y los hábitos más antiguos persisten. Pero es importante recordar cómo Lenin y Kollontai libraron batallas fuertes contra esto. Lenin tiene una critica deslumbrante a sus camaradas varones del Partido Bolchevique cuando les dice: ¿qué estás haciendo, dejando que tu compañera mujer se ocupe de este tipo de tareas mientras vos te ocupás de las tareas políticas? Lenin y Kollontai son bien claros en esto: ellos conformaron una comisión con el objetivo de incorporar más mujeres a la vida política. Lo que es importante que entendamos es que más allá de los condicionantes del momento, hubo un esfuerzo de los viejos bolcheviques por cambiar esa situación. Y ese muy corto período

17. Véase Arruzza, Bhattacharya y Fraser (2019).

18. Véase Goldman (2010). 
se transformó en un período de intensa experimentación. Nada de eso llegó a prosperar y la contrarrevolución de Stalin barrió con todo, pero tenemos que recordar ese período.

Quisiera finalizar hablando de dos hechos de los que normalmente no se habla. El primero es que la Revolución Rusa fue comenzada por mujeres que marchaban por pan. Eso dio comienzo a la revolución y es lo primero que tenemos que recordar. Lo segundo es el tipo de confianza que la Revolución Rusa le dio a las mujeres durante este periodo de experimentación. Por ejemplo, cada vez que ocurría un caso de acoso sexual por parte de jefes o de compañeros trabajadores varones, las mujeres trabajadoras ponían a esos hombres en una carretilla, los llevaban al río y los tiraban allí. Menciono esto porque quisiera pensar nuestras luchas presentes a partir de estos dos hechos de la Revolución Rusa: exigimos pan para nuestras mesas y carretillas para nuestros enemigos.

\section{Referencias}

Arruzza, C. (2010). Las sin parte: matrimonios y divorcios entre feminismo y marxismo. Traficantes de Sueños.

Arruzza, C. (2015). Funcionalist, Determinist, Reductionist: Social Reproduction Feminism and its Critics. Science \& Society, 80 (1), 9-30.

Arruzza, C., Bhattacharya, T. y Fraser, N. (2019). Manifiesto por un feminismo del 99\%. Rara Avis.

Benston, M. (1969). The Political Economy of Women Liberation. Monthly Review, 21, 4, 13-27.

Bhattacharya, T. (2017). Social Reproduction Theory: Remapping Class, Recentering Oppression. Pluto Press.

Brenner, J. y Laslett, B. (1991). Gender, Social Reproduction, and Women's Self Organization: Considering the US Welfare State. Gender \& Society, 5, 3, 311-333.

Caffentzis, G. y Federici, S. (2018). Comunes contra y más allá del capitalismo. En G. Caffentzis (ed.), Los limites del capital. Deuda, moneda y lucha de clases. Tinta Limón-Fundación Rosa Luxemburgo.

Drucker, P. (2015). Warped: Gay Normality and Queer Anti-Capitalism. Brill. Engels, F. (1845). La situación de la clase obrera en Inglaterra. Disponible en https://www.marxists.org/espanol/m-e/1840s/situacion/situacion. pdf.

Ferguson, S. (2020). Women and Work. Feminism, Labour and Social Reproduction. Pluto Press.

Goldman, W. (2010). La mujer, el estado y la revolución. Ediciones IPS.

Harvey, D. (2004). El nuevo imperialismo. Akal.

Hirata, H. y Kergoat, D. (1997). La división sexual del trabajo: permanencia y cambio. Trabajo y Sociedad. 
Kergoat, D. (2003). De la relación social de sexo al sujeto sexuado. Revista Mexicana de Sociología, 65, 4.

Rediker, M. (2007). The Slave Ship: a Human History. Viking Penguin.

Roberts, D. (1997). Killing the Black Body: Race, Reproduction and the Meaning of Liberty. Vintage by Random House.

Sears, A. (2017). Body Politics: the Social Reproduction of Sexualities. En T. Bhattacharya (ed.), Social Reproduction Theory: Remapping Class, Recentering Oppression. Pluto Press.

Varela, P. (2018). Sobre la relación entre género y clase. Entrevista con Tithi Bhattacharya. Ideas de Izquierda, 44.

Vogel, L. (2013). Marxism and the Oppression of Women. Historical Materialism.

Wiesner-Hanks, M. (2001). Cristianismo y sexualidad en la Edad Moderna. La regulación del deseo, la reforma de la práctica. Siglo XXI. 